\title{
Configurações
}

Revista de sociologia

\section{Um trabalho pós-memorial: o caso de Daniel Blaufuks}

A post-memorial work: the case of Daniel Blaufuks

Un travail postmémorial: le cas de Daniel Blaufuks

\section{Ana Quintais}

\section{OpenEdition}

\section{Journals}

\section{Edição electrónica}

URL: http://journals.openedition.org/configuracoes/3291

DOI: 10.4000/configuracoes.3291

ISSN: 2182-7419

\section{Editora}

Centro de Investigação em Ciências Sociais

\section{Edição impressa}

Data de publição: 27 Junho 2016

Paginação: 199-210

ISSN: 1646-5075

\section{Refêrencia eletrónica}

Ana Quintais, « Um trabalho pós-memorial: o caso de Daniel Blaufuks », Configurações [Online],

17 | 2016, posto online no dia 30 junho 2016, consultado o 30 abril 2019. URL : http:// journals.openedition.org/configuracoes/3291 ; DOI : 10.4000/configuracoes.3291 
Quintais, Ana - Um trabalho pós-memorial: o caso de Daniel Blaufuks.

Configurações, vol. 17, 2016, pp. 199-210

\title{
Um trabalho pós-memorial: o caso de Daniel Blaufuks
}

\author{
ANA QUINTAIS*
}

\section{Resumo}

Partindo da noção de pós-memória reflete-se sobre memória, família e fotografia, bases fundamentais na construção conceptual do termo formulado por Marianne Hirsch. Entre a geração pós-memorial, ligada aos eventos do Holocausto, destaca-se o fotógrafo e artista visual português Daniel Blaufuks que, através das obras Sob Céus Estranhos (2007) e Terezín (2010), ilustra exemplarmente alguns dos pressupostos de um trabalho de pós-memória.

Palavras-chave: pós-memória, fotografia, memória, família, Daniel Blaufuks.

\begin{abstract}
A post-memorial work: the case of Daniel Blaufuks

Starting from the notion of post-memory, this article discusses memory, family and photography, which are foundational concepts in the construction of the term "post-memory" as formulated by Marianne Hirsch. Among the post-memorial generation connected with the events of the Holocaust, Portuguese photographer and visual artist Daniel Blaufuks stands out, notoriously illustrating through his Sob Céus Estranhos (2007) and Terezin (2010) some of the assumptions of a post-memory work.
\end{abstract}

Keywords: postmemory, photography, memory, family, Daniel Blaufuks.

\section{Résumé}

\section{Un travail postmémorial : le cas de Daniel Blaufuks}

Partant de la notion de postmemory (Hirsch), cet article traite de la mémoire, de la famille et de la photographie, bases fondamentales dans la construction conceptuelle du terme formulé par Marianne Hirsch. On distingue, dans la génération postmemorielle

* Investigadora independente, doutorada em Linguagens e Heterodoxias - ramo Estudos Anglo-Americanos pela Faculdade de Letras e CES da Universidade de Coimbra. Email: anaserip@gmail.com. 
liée aux évènements de la Shoah, le photographe et artiste visuel portugais Daniel Blaufuks, qui illustre remarquablement certains des présupposés du travail de la postmémoire dans Sob Céus Estranhos (2007) et Terezín ( 2010 ).

Mots-clés: postmémoire, photographie, mémoire, famille, Daniel Blaufuks.

1. Marianne Hirsch postula um conceito em torno do que significa crescer numa família na qual um ou mais elementos são sobreviventes ${ }^{1}$ do Holocausto ${ }^{2}$. A autora invoca a sua experiência como filha de dois sobreviventes para construir um corpus teórico que tem em conta a noção de trauma e a sua hipotética transmissibilidade, cabendo à família o papel instrumental desta transmissão.

Para os sobreviventes de eventos coletiva e culturalmente traumáticos, como é o caso do Holocausto, a memória não se assume somente como um ato de recordação ou de evocação do passado, mas também como um ato de luto, frequentemente marcado por sofrimento, desespero e raiva. Segundo Hirsch (1996: 662), o sofrimento consequente não atinge apenas os indivíduos que testemunharam em primeira mão tais eventos, mas também os seus descendentes, introduzindo o conceito de "pós-memória". Pós-memória descreve, assim, o relacionamento que a geração posterior àquela que vivenciou um evento traumático tem com tal experiência. Desta forma, a segunda ou terceira geração lembra-se, não porque esteve lá, mas porque estando imersa numa determinada narrativa familiar é-lhe transmitido o trauma experienciado pela primeira geração.

As recordações dos eventos ocorridos e vivenciados pela primeira geração são, assim, atualizados nos seus descendentes através das memórias transmitidas pelos pais e/ou pelos avós sob a forma de histórias, narrativas, comportamentos e imagens. Crescer com tais recordações respeitantes a acontecimentos que não foram vividos pelo próprio, mas que, de todo o modo, fazem parte da sua memória, transformam e moldam toda uma geração pós-memorial.

O conceito de pós-memória é distinto do de memória ao colocar a tónica no distanciamento temporal, no deslocamento e no "pós” ou "após”. Tal como noutros conceitos com o mesmo prefixo, pós-memória caracteriza-se por um olhar retrospetivo de forma a contextualizar um presente, demarcando-se de

1 A definição de sobrevivente de Holocausto que será usada ao longo do presente texto tem em conta a noção proposta por Arlene Stein (2009), e que compreende os judeus que viveram sob a ocupação nazi durante a Segunda Guerra Mundial e que sobreviveram. Esta definição abrange, assim, não só aqueles que viviam na Alemanha, na altura da guerra, como em qualquer país posteriormente ocupado pelas forças nazis. Também compreende judeus que foram internados em campos de concentração, aqueles que permaneceram escondidos e os que lograram fugir para outros países antes de a possibilidade de fuga ser praticamente impossível.

2 Diversos autores apresentam problemas na utilização do conceito de Holocausto dada a sua evocação do divino e do sagrado (Mandel, 2001), pressupondo uma ideia, derivada da sua etimologia, de sacrifício expiatório (Ribeiro, 2008). Optou-se, contudo, pela decisão de empregar esta expressão no presente texto pelo facto de esta palavra se encontrar "firme e inerradicavelmente instalada no uso corrente." (7). 
uma rutura radical e aliando-se a uma aporia que balança entre a continuidade e a quebra. Pós-memória pode ser descrita através de uma ideia de imaginação e de criação que caracteriza a ligação da pós-memória a um passado, ao invés de um ato de recordação presente na memória. Este processo parece exigir sempre uma forma de ligação ou de conexão, criando e imaginando onde não se pode reparar nem recordar, ao mesmo tempo que se faz o luto pelo destruído. Um luto que, no entanto, não pode ser nunca concluído ou finalizado (664). Pós-memória não é, pois, sinónimo de memória, daí o prefixo, aproximando-se antes da memória de forma afetiva, através de "memórias herdadas" (Hirsch, 2008: 107), feitas de imagens e de silêncios, de uma linguagem familiar que é também corporal, e que constituem a substância da pós-memória. A linguagem familiar é entendida aqui como uma forma de expressão que contempla um conjunto de sintomas provenientes de uma experiência verdadeiramente traumática: pesadelos, lágrimas, doenças, males que constituem a herança das condições terríveis a que a primeira geração esteve sujeita durante os anos de perseguição (112).

$\mathrm{Na}$ formulação da pós-memória, a família manifesta-se, assim, como um dos principais meios de transmissão da memória, possibilitando uma transmissão intergeracional da memória. Distingue-se entre transmissão intergeracional e transgeracional (ou intrageracional) da memória, associando esta última com uma ideia de identificação ou de reconhecimento por afinidade (114). Nesta identificação, neste reconhecimento (ou olhar) por afinidade 3 radica uma conceção de carácter coletivo, um alargamento do círculo pós-memorial para além dos descendentes dos sobreviventes dos eventos traumáticos. Enquanto a transmissão intergeracional tem em conta uma transmissão de conhecimento dentro de uma família, de geração para geração, a transmissão transgeracional da memória explica-se através de uma estrutura de transmissão horizontal - pressupondo uma identificação por afinidade entre indivíduos da mesma geração ou contemporâneos dos descendentes dos sobreviventes. Desta forma, pós-memória pode ser descrita como uma estrutura de transmissão inter e transgeracional do conbecimento e da experiência traumática. Nesta estrutura de transmissão inter e transgeracional que caracteriza a pós-memória são destacados três elementos considerados fundamentais: memória, família e fotografia (108).

O processo de pós-memória coloca a vida familiar num imaginário coletivo associado a arquivos de histórias e imagens públicas que são partilhadas e que afetam a transmissão das lembranças familiares e individuais. Não é, pois, de estranhar que muitas das expressões artísticas dos descendentes de sobreviventes e vítimas do Holocausto utilizem o idioma familiar, uma espécie de língua franca que irá permitir a identificação e o reconhecimento por parte de um público que não tem ligações óbvias aos sobreviventes dos acontecimentos 
traumáticos ou aos seus descendentes, facilitando assim, uma transmissão transgeracional da memória.

De modo a ilustrar a formulação do processo de pós-memória, Hirsch (1996: 668) apresenta o Holocaust Memorial Museum em Washington, nos Estados Unidos. Na perspetiva da autora, este museu destina-se não só aos descendentes dos sobreviventes e vítimas do Holocausto, como a todos aqueles que não tendo ligações diretas aos eventos em si, sentem vontade de conhecer e saber mais sobre um passado que inevitavelmente diz respeito a todos nós, que viemos depois.

A forma que o Holocaust Memorial Museum encontrou para conseguir transmitir um pouco do mundo entretanto desaparecido, de uma cultura praticamente destruída e de toda a violência que se abateu sobre aqueles que foram perseguidos pelo regime nazi, processou-se através de exposições fotográficas com imagens que tentam retratar estas mesmas vidas e culturas, possibilitando a consideração da importância da fotografia no trabalho de pós-memória. As fotografias são frequentemente lidas como evidências, como traços de um passado, estabelecendo ligações materiais - são ícones e índices -, tanto com esse passado perdido, como com as pessoas que não sobreviveram e que se encontram representadas fotograficamente. Trata-se do ça a été mencionado por Roland Barthes (2006 [1980]), e que Hirsch invoca para reforçar a ligação entre memória e pós-memória facilitada pelo registo fotográfico (674). Desta forma, a fotografia assume-se como um medium particularmente valioso para a noção de pós-memória.

A exposição intitulada Tower of Faces presente no Holocaust Memorial Museum é descrita como um álbum familiar cujas fotografias e legendas são reconhecidas na sua convencionalidade e familiaridade por todos aqueles que têm ou não uma ligação aos eventos retratados. Estas fotografias tornam-se, então, do domínio do conhecido e do familiar, permitindo simultaneamente um olhar por afinidade e um olhar familiar que possibilita uma interligação coletiva, transformando estas histórias individuais numa história de memória coletiva e alargando, deste modo, o círculo pós-memorial. Um reconhecimento que se explica através das próprias características do álbum de família: qualquer pessoa terá na sua posse uma fotografia semelhante àquelas que se podem encontrar na instalação Tower of Faces. São imagens fotográficas que mostram um mundo antes da guerra, um mundo onde famílias judias comemoram despreocupadamente um aniversário, um casamento, uma reunião familiar. As fotografias que sobreviveram à devastação do Holocausto e aos seus próprios sujeitos constituem uma espécie de emanação fantasmagórica, ao mesmo tempo que evocam um passado e/ou um mundo irrecuperável. Este lado fantasmático é característico de todas as fotografias que retratam pessoas que já morreram. Contudo, quando se sabe dos eventos que conduziram aquelas pessoas à morte, quando se conhece a dimensão violenta da morte que as levou, as fotografias 
das vítimas do Holocausto parecem assumir um aspeto suplementar de horror. Como se a fotografia pudesse testemunhar a sua própria violência, uma violência que não é visível mas que é percebida através do carácter indicial da imagem fotográfica que, desta forma, se assume como documento e arquivo de um corpo destruído.

As fotografias de destruição e as fotografias de família no contexto do Holocausto afiguram-se como documentos, evidências de participação na história, documentos de memória (das vítimas) e de pós-memória (dos descendentes). Para Hirsch (2012 [1997]), há todo um conjunto de características da imagem fotográfica que lhe permite ser o meio preferencial escolhido pela geração pós-memorial no exercício da pós-memória e, assim, ir no encalço da primeira geração. Esta ideia implica uma recolha de pistas e evidências deixadas pelos elementos da primeira geração, vestígios descobertos e/ou desenterrados em lugares e/ou objetos do passado, como as fotografias. Em referência ao fotógrafo francês do princípio do século XX, Eugène Atget, Walter Benjamin (1992 [1955]: 219-20) chama a atenção para a forma como as fotografias parecem sugerir locais de crime, imagens que mostram lugares desertos cheios de possíveis provas de algo que é importante investigar. Como se a fotografia pudesse esconder algo que escapa ao olho nu de quem observa (o "inconsciente ótico"), um segredo que parece gritar para ser revelado. A fotógrafa Diane Arbus caracteriza a fotografia como "um segredo de um segredo" (apud Coignet, 2012: $\mathrm{s} / \mathrm{p}$ ), sublinhando o estatuto indicial da fotografia, a sua condição fragmentária, tornando-a aberta a múltiplas interpretações e dando-lhe um carácter fortemente subjetivo e autobiográfico.

As fotografias que mostram famílias judaicas numa época anterior à Segunda Guerra Mundial constituem um vestígio indicial de pessoas que muito provavelmente não sobreviveram, representando, desta forma, um meio de ligação entre a memória e a pós-memória, entre um mundo desaparecido e o mundo depois de Auschwitz. É neste contexto que o álbum de fotografias de família assume um papel relevante na elaboração do trabalho de pós-memória. Segundo Hirsch (1996: 671) é precisamente devido à convencionalidade e familiaridade da fotografia de família - um reconhecimento que apaga as marcas do tempo e do espaço, porque todos possuímos fotografias familiares e álbuns de família - que torna impossível a compreensão do sucedido, de como a pessoa da fotografia pôde ser exterminada. Aqui, o observador preenche aquilo que a fotografia não mostra: o conhecimento do futuro das pessoas que aparecem na imagem fotográfica. É a catástrofe da fotografia segundo Barthes (2006 [1980]: 107), o conhecimento avassalador da morte no futuro, o punctum de determinadas fotografias que parece esmagar quem observa e lê a imagem fotográfica. 2. Os temas tratados por Daniel Blaufuks não são indiferentes à sua história familiar. Nascido em Lisboa no ano de 1963, Daniel Blaufuks é neto de refugiados judeus alemães e polacos. Enquanto os avós de origem polaca chegaram 
a Portugal nos anos 20, os avós alemães instalaram-se em Lisboa pouco antes do início da Segunda Guerra Mundial. Declarando que "depois de Auschwitz somos todos judeus" (apud Seixas, s/d: s/p), o artista português afirma sentir-se judeu desde sempre, tanto mais que o judaísmo dos avós maternos é a razão pela qual Blaufuks nasce em Portugal, a razão pela qual dá mais atenção ao que se passa no mundo, ao que acontece com outras minorias:

O Holocausto reforçou essa filiação histórica. O meu avô viveu amargurado por ter sido posto de lado, por ter sido posto fora de uma comunidade a que ele julgava pertencer e onde se sentia perfeitamente integrado, e que era a comunidade alemã, não a judaica. Isso foi o que mais os surpreendeu! (s/p).

Blaufuks assume uma tendência literária presente nas suas fotografias com um natural lado autobiográfico (Mah, 2006: s/p), fotografias que conduzem às histórias que o artista pretende contar e às suas próprias experiências, como as viagens que realiza e que perceciona como uma espécie de busca, ou como uma procura que também encontra na fotografia: “Os verdadeiros viajantes, tal como muitos fotógrafos, sabem que não vão encontrar aquilo que procuram. O que lhes interessa é a experiência, é o percurso" (s/p). Neste percurso através da imagem o artista sublinha a importância que dá à história da fotografia e às imagens dos outros que muitas vezes utiliza nos próprios trabalhos, uma apropriação assumida e explicada através do fascínio e sedução que estes trabalhos e artistas despertam em Blaufuks. Talvez seja um pouco à semelhança de Barthes (1975: 9), quando este refere que não sabe exatamente porque é que determinadas imagens o perturbam, avançando com a possibilidade da "ignorância própria do fascínio", para logo rematar com as imagens da sua juventude como aquelas que mais o interessam e perturbam. Do mesmo modo, nos trabalhos de Blaufuks encontramos amiúde imagens antigas, porventura, imagens(-ícone) da sua juventude. Em Combo (2004) os objetos que se observam são deste tipo de imagem, imagens icónicas de artistas ligados à música e ao cinema, como Elvis Presley, Bob Dylan, Jean Seberg, figuras pertencentes à memória afetiva de uma determinada geração.

De acordo com Hirsch (2008: 106), o trabalho da pós-memória tem, efetivamente em conta a prática da citação e da mediação, caracterizando-se por um olhar em retrospetiva ao definir o presente em função de um determinado passado. Nesta prática da citação parece estar integrada uma das técnicas mais frequentes no trabalho de Blaufuks, a de re-fotografar e/ou re-filmar imagens que não são da sua autoria. Poder-se-ia falar de uma "autoria partilhada" nas palavras de Mark Gisbourne (2008: 85), na qual se usa um texto literário, um título, uma canção, uma fotografia ou uma descrição de uma fotografia, um filme ou partes de um documentário para construir a sua própria obra. Isto parece também ligar-se à própria ideia da memória privada, uma memória 
que individual se constrói, se forma, a partir de maiores enquadramentos, a partir de uma memória pública. Uma obra que se constitui a partir de outras obras. De facto, uma das características do trabalho de pós-memória assenta nesta espécie de reutilização de imagens públicas, imagens icónicas que são do conhecimento de um público mais alargado e que são usadas pelos agentes de pós-memória de forma a articular as suas próprias memórias privadas. Usando informação veiculada publicamente, informação que faz parte de um imaginário coletivo, de uma cultura de massas, o agente de pós-memória reinveste as memórias familiares, integrando-as e assimilando-as de uma forma que parece ser inseparável deste conhecimento público.

É nesta espécie de eixo entre o público e o privado que encontramos constantemente na obra de Blaufuks objetos, fotografias e palavras que remetem para um re-memorar do passado que pode estar inscrito na aparente inocência de fotografias de infância, numa certa convencionalidade dos álbuns de família ou mesmo em imagens que refletem os acontecimentos que fazem parte, não só da história do nosso país, como da própria história mundial. Um agente de pós-memória pegará inevitavelmente em memórias dos outros, das suas experiências, invocando-as, recordando-as, retirando-as da sombra dos seus passados. Atualizando-as no presente. Blaufuks explica o processo de re-fotografar como uma "necessidade técnica" (apud Mah, 2006: 3), uma forma de olhar para o passado (são habitualmente fotografias e imagens antigas) à $l u z$ do presente (porque quase sempre acrescenta algo), ligando o artista ao conceito de pós-memória. Nesta investida ao passado com os pés assentes no presente, Blaufuks pode ser encarado como um artista-historiador (van Alphen), um artista-arquivista (Foster), um artista visual que investiga e produz um trabalho de memória (Kuhn), apresentando, como o próprio diz, "uma memória de uma memória de outra memória" (3), e que pode ser a caracterização perfeita do que significa ser um elemento de terceira geração pós-memorial.

Sob Céus Estranhos. Uma História de Exílio (2007) aparece no seguimento de uma média metragem documental com o mesmo título e realizada em 2002, onde Blaufuks traça a história dos seus avós maternos desde que viajam da cidade alemã de Magdeburgo até Lisboa no ano de 1936, fugindo deste modo "da terra de Hitler" e encontrando na capital portuguesa um tão desejado "porto de abrigo". O título do livro que junta fotografia, filme, texto e documentos de arquivo é retirado da obra homónima de Ilse Losa que conta a história de um judeu alemão a viver na cidade do Porto durante a Segunda Guerra Mundial. No seu livro, Blaufuks conta que cresceu no mesmo prédio dos avós. Com eles passava o serão e com eles tomava as refeições, crescendo ao som de histórias, em redor de objetos e entre memórias que, não sendo suas, não deixaram por isso de ser integradas e adotadas como parte da sua identidade. Blaufuks folheia-nos o seu álbum de família contando a história do exílio forçado dos seus avós maternos em Portugal em estreita relação com a história 
do país governado por Salazar. As fotografias de família encontradas em Sob Céus Estranhos parecem garantir a presença dos entes queridos do autor num momento eternizado não só pelo take fotográfico como pelo próprio trabalho de Blaufuks ao incluí-las em filme e em livro. A fotografia enquanto dispositivo tecnológico que faz uso de um estatuto indicial ao expor uma relação poderosa entre a imagem e o referente oferece a promessa de aceder ao próprio evento (Hirsch, 2008: 107). Isto faz da fotografia o meio, por excelência, do trabalho de pós-memória, ao estabelecer essa ligação do presente ao passado. Mais do que documentos escritos ou testemunhos orais, as imagens fotográficas funcionam como "emanações fantasmáticas de um mundo irremediavelmente perdido" (115, tradução minha). Desta forma, ao apresentar Portugal sob a forma de imagens e documentos da época, juntamente com as fotografias dos avós, Blaufuks parece cumprir eficazmente aquilo que Hirsch caracteriza como trabalho pós-memorial: um trabalho que "reativa e reincorpora" (111) memórias públicas e de arquivo ao investi-las através de mediações estéticas com forte cunho pessoal e familiar. Isto quer dizer que as experiências da primeira geração não são apenas resgatadas do esquecimento, como são transmitidas a quem tenha um ouvido empático, "participantes menos diretamente afetados" (115, tradução minha) e que acabam por se incluir na geração pós-memorial. Comenta Blaufuks em entrevista a Pedro Caiado e Pedro Treno (2014): “Não é por acaso que trabalho sobre temas como o Holocausto (tem que ver diretamente com a minha família) [...] A memória também tem um prazo de validade [...] o que é perigoso porque acabamos por voltar sempre aos mesmos sítios" (63). Talvez para prevenir o retorno "aos mesmos sítios" do passado ou o retorno desses escusos sítios, Blaufuks insista numa necessária transmissão que confere importância à fotografia como meio de excelência para a memória: "No fundo, é isso que me interessa, a transmissão ao longo dos tempos que, no fundo, é a memória: utilizar vários métodos fotográficos para combinar a memória de todos esses tempos. [...] a montagem para mim é [...] uma ideia de transmissão: de mim para quem vai ver e também geracional” (57). E esta ideia de transmissão é sublinhada especialmente em Sob Céus Estranhos, não só quando descobrimos o gosto pela fotografia do avô de Blaufuks, como pela própria composição da obra, parte fotografia e filmes de família (da autoria do avô Herbert), parte documentos encontrados em arquivos, jornais, postais que passaram de geração em geração, fazendo de Blaufuks um verdadeiro portador de memórias.

Um portador de memórias será, então, alguém que transmite as memórias de outrem, será um agente de pós-memória cuja responsabilidade é garantir que o conhecimento dos eventos seja transmitido às gerações futuras. Este conhecimento tem sido expresso sob diversas formas artísticas por diferentes atores unidos e ligados por algo muito poderoso e que os torna pertencentes a uma geração pós-memorial: a “memória secundária” de um trauma não vivido 
que necessita de ser elaborado. O dispositivo que permite unir a geração do Holocausto à geração que vem depois é a fotografia, dado que esta é uma tecnologia cujas características oferecem, então, uma promessa de acessibilidade ao passado e com este, ao próprio evento. A fotografia é, pois, um meio poderoso de transmissão dos acontecimentos trágicos e violentos ocorridos no passado ao mesmo tempo que apela a uma narrativa ancorada no olhar subjetivo do seu observador. Blaufuks parece proceder a esta transmissibilidade ao criar Terezín que publicará em 2010. Partindo de uma fotografia encontrada em Austerlitz do escritor alemão W.G. Sebald ${ }^{4}$, o artista português narra uma viagem ao antigo campo de concentração de Theresienstadt ao mesmo tempo que explica as origens e a história desta cidade fortificada situada a norte de Praga, na República Checa. Imagens de arquivo da cidade e depois enquanto campo de concentração são inseridas em conjunto com as fotografias mais recentes e tiradas por Blaufuks no local. Ao fazer confluir passado e presente (ou passado mais recente) através destas imagens fotográficas, Blaufuks re-ativa e re-incorpora aquilo que Hirsch (2008: 111) designa de "estruturas sociais e/ou nacionais e de arquivo e/ou culturais de memória” e que caracteriza todo o trabalho de pós-memória.

Tal como em Sob Céus Estranhos, Blaufuks adiciona ao material fotográfico documentos de arquivo, um filme-documentário, imagens de objetos e páginas de um diário. Se no trabalho anterior essa narrativa tinha sido impulsionada pela leitura do diário de Herbert August, em Terezín seguimos a história de Ernst K. de quem conhecemos algumas páginas do diário. Ao incluir a narrativa de Ernst, Blaufuks faz uma ligação afetiva ao passado através da memória do jovem judeu inscrita nas páginas do diário e nos objetos que eram seus. Personalizando e exibindo imagens visuais da história o artista português consegue transmitir ao leitor toda a violência do ocorrido, confirmando o que Hirsch teoriza sobre a fotografia como um meio fundamental para a transmissão transgeracional do trauma.

A imagem que serve de mote a Terezín é, em si mesma, um exemplo do tipo de fotografia que Blaufuks tem realizado ao longo do seu percurso. Esta é uma imagem de uma imagem, feita através de um re-fotografar, originada numa imagem encontrada num livro ${ }^{5}$. Nesta ação de re-fotografar é possível encontrar dois pontos importantes que permitem, porventura, compreender algumas das intenções do trabalho do artista português: o primeiro diz respeito à importância que Blaufuks dá à literatura, uma forma de arte que, no seu caso, parece

4 Marianne Hirsch e Leo Spitzer (2006) fazem referência a um conjunto de escritores e artistas que têm vindo a desenvolver um trabalho que reflete uma forte estética memorial, entre os quais se destaca W. G. Sebald, e que constituem aquilo que os autores denominam de geração de pós-memória.

5 A imagem encontrada em Austerlitz apresenta-se pouco nítida, a preto e branco, com muito grão, assemelhando-se mais a uma fotocópia e que mostra um espaço de trabalho, um escritório ou um arquivo. Na viagem que faz a Terezín, Blaufuks encontra o mesmo espaço que é retratado na fotografia de Austerlitz e o primeiro impulso é registá-lo fotograficamente. 
fundir-se naturalmente com a prática da fotografia. É o próprio que refere a proximidade entre a fotografia e a literatura, mais até do que da pintura ou da escultura (Blaufuks, 2008: 22). Por outro lado, e ao longo da sua carreira, Blaufuks tem feito questão em publicar livros que funcionam como catálogos e que juntamente com as suas exposições/instalações permitem mostrar toda a potencialidade da imagem fotográfica. Um segundo ponto importante que se pode retirar deste impulso em re-fotografar uma imagem prende-se com a questão da autoria. Para produzir a fotografia na sua mente, Blaufuks parte de uma imagem de autoria desconhecida (na altura) ${ }^{6}$ encontrada num livro de um autor que pertence a uma segunda geração pós-memorial/pós-Holocausto, de um lugar que podia ser o de um campo de concentração (pelo contexto da narrativa do livro) e (re) fotografa no mesmo local, produzindo uma (outra) fotografia semelhante àquela com que parte. Esta re-leitura, esta apropriação do trabalho de alguém, poderá incluir-se naquilo que Foster (2004) denomina de "conhecimento alternativo" (4, tradução minha). Em vez de pegar numa peça ou num trabalho conhecido (do grande público), Blaufuks agarra numa imagem que só será reconhecida por alguns (serão aqueles que leram Austerlitz e se recordam dessa imagem em específico) para produzir uma outra imagem. Mas mais do que pegar num autor ou numa imagem mais ou menos obscuros, Blaufuks utiliza uma fotografia encontrada num livro de um autor que é, também ele, agente de pós-memória. Por outro lado, apropriando-se de uma imagem já existente e re-criando-a como sua, está a produzir pós-memória, uma vez que tenta re-encenar a memória do ocorrido. Se os ficheiros representados na imagem indicam a destruição metódica levada a cabo pelos nazis, re-fotografar uma imagem que refere um lugar, nesse mesmo lugar procurando um mesmo enquadramento e ponto de vista, pode mostrar a dificuldade em testemunhar o ocorrido.

Poder-se-á talvez falar de um universo de imagens familiares para aqueles que trabalham sobre a memória do Holocausto ou que pertençam a uma segunda e terceira geração pós-memorial, como é o caso de W.G. Sebald e de Blaufuks, respetivamente. Parece haver uma certa ideia de "ir na peugada" de alguém, mas há também, nessa reutilização de objetos imaginários, uma reafirmação do trabalho de memória e ainda - principalmente, através do uso de imagens - de uma aceitação da dificuldade no uso da palavra ou da narração do sucedido.

A obra artística de Daniel Blaufuks obedece, assim, claramente, aos pressupostos do trabalho de pós-memória postulado por Marianne Hirsch. De facto, são os próprios elementos que servem de alicerce ao trabalho pós-memorial - memória, fotografia e família - que cimentam o percurso de

6 Mais tarde, Blaufuks descobrirá tratar-se de uma imagem pertencente a Dirk Reinartz, um fotógrafo alemão. 
Blaufuks. O seu impulso para contar histórias encontra-se relacionado com um conhecimento adquirido num contexto familiar fortemente marcado pelos acontecimentos catastróficos que fazem parte da história coletiva do século XX. Um re-contar que se associa a arquivos de imagens e de biografias públicas e anónimas, que afetam a forma como o artista transmite as suas memórias. Uma transmissão que tem subjacente a intenção de alcançar o maior número de ouvintes, tenham estes ou não ligações diretas com os acontecimentos que se fazem associar à transmissão intra ou transgeracional defendida por Hirsch do trabalho pós-memorial. Blaufuks consegue passar o conhecimento e informação incluídos nas memórias transmitidas, assegurando o seu lugar enquanto elemento de uma geração pós-memorial, ou seja, uma geração que, efetivamente, se encontra num espaço de charneira, sentindo a urgência de transmissão dos eventos traumáticos vividos pelos seus antepassados. Esta representação não passa pela encenação ou narração do sucedido, mas antes pela experiência do que significa viver com quem testemunhou, com quem sofreu os eventos traumáticos. Atenta-se ao que aconteceu depois do evento, trabalhando com fragmentos e fantasmas. Por outro lado, o artista português assume-se como alguém que produz uma "memória de uma memória de uma memória”, ligando as memórias dos seus avós maternos às suas numa cadeia de transmissão por onde faz circular imagens, objetos, lugares, espaços e tempos, passíveis de serem codificados em fotografia e palavra. É deste modo que a transmissão intergeracional do trauma se realiza, atualizando, na terceira geração, o trauma por resolver do sobrevivente do Holocausto, um trauma que pode assumir a imagem de uma ferida, de uma ausência ou de uma constante sensação de desenraizamento.

\section{Referências}

BARTHES, Roland (2006), A Câmara Clara. Nota Sobre a Fotografia. Lisboa: Edições 70. (1980). BARTHES, Roland (1975), Roland Barthes por Roland Barthes. Lisboa: Edições 70.

BENJAMIN, Walter (1992), Illuminations, in Hannah Arendt (ed.). London: Fontana Press. (1955). BLAUFUKS, Daniel (2010), Terezín. Lisboa, Göttingen: Edições Tinta da China \& Steidl Publishers. BLAUFUKS, Daniel (2008), O Arquivo, The Archive. Um álbum de textos. An album of texts. Lisboa: Vera Cortês agência de arte.

BLAUFUKS, Daniel (2007), Sob Céus Estranhos. Uma História de Exílio. Lisboa: Edições Tinta da China.

BlaUfuKS, Daniel; CAIADO, Pedro; TRENO, Pedro (2014), "À conversa com Daniel Blaufuks". Revista nu, 42: 56-67.

COIGNET, Rémi (2012), “Une conversation avec Daniel Blaufuks”, disponível em http://deslivresetdesphotos.blog.lemonde.fr/2012/01/12une conversation-avec-daniel-blaufuks [consultado em 20.08.2012].

FOSTER, Hal (2004), “An Archival Impulse”. October,110: 3-22.

GISBOURNE, Mark (2008), “A polifonia da memória e a dissonância do arquivo”, in Daniel Blaufuks, O Arquivo, The Archive. Um álbum de textos. An album of texts. Lisboa, Vera Cortês agência de arte, 83-90. 
HIRSCH, Marianne (2012), Family Frames: Photography, Narrative and Postmemory. Cambridge, Massachusetts: Harvard University Press. (1997).

HIRSCH, Marianne (2008), “The Generation of Postmemory”. Poetics Today, 29 (1): 103-28.

HIRSCH, Marianne (1996), "Past Lives: Postmemories in Exile”. Poetics Today, 17 (4): 659-86.

HIRSCH, Marianne; SPITZER, Leo (2006), "What's Wrong with This Picture? Archival Photographs in Contemporary Narratives”. Journal of Modern Jewish Studies, 5 (2): 229-252.

MAH, Sérgio (2006), “Uma Conversa Com Sérgio Mah”, disponível em http://danielblaufuks. com/webmac/text/conversa.html [consultado em 19.10.2012].

MANDEL, Naomi (2001), "Rethinking “"After Auschwitz": Against a Rhetoric of the Unspeakable in Holocaust Writing”. Boundary 2, 28 (2): 203-28.

RIBEIRO, António Sousa (2008), "Cartografias do Não-Espaço: Viagens ao Fim do Mundo na Literatura do Holocausto". Revista Crítica de Ciências Sociais, 83: 5-18.

SEIXAS, Maria João (s/ data), “Conversa com vista para”, disponível em http://www.danielblaufuks.com/webmac/extras/seixas.html [consultado em 20.08.2012].

STEIN, Arlene (2009), "Trauma and Origins: Post-Holocaust Genealogists and the Work of Memory”. Qual Sociol, 32: 293-309.

Submetido: 27-02-2016

Aceite: $19-05-2016$ 